\title{
Adjustments of Methodology Planning and Assessment Activities of Senior Projects in the Computer Science Program
}

\author{
Mai A. Fadel ${ }^{1}$ \\ ${ }^{1}$ Computer Science Department, Faculty of Computing and Information Technology, King Abdulaziz University, \\ Jeddah, Saudi Arabia \\ Email:mfadel@kau.edu.sa \\ Lamiaa A. Elrefaei ${ }^{1,2}$ \\ ${ }^{2}$ Electrical Engineering Department, Faculty of Engineering at Shoubra, Benha University, Cairo, Egypt \\ Email: laelrefaei@kau.edu.sa, lamia.alrefaai@feng.bu.edu.eg
}

Received: 29 December 2017; Accepted: 15 January 2018; Published: 08 February 2018

\begin{abstract}
The senior project stage in bachelor's degrees represents an essential milestone in the learning process of a Computer Science (CS) student. The Senior Project Management System (SPMS) plays an important role in refining the quality of the resulting product and improving the learning experience of students. The CS department at King Abdulaziz University (KAU) has followed a well-defined system for managing senior projects since 2012. Systems evolve through time in response to encounters that unfold when the system is put to use. The administration of CS senior projects is no exception. In this paper, we present some incremental changes that have been introduced as refinements to the original system. This paper focuses on analyzing the data of the projects conducted during 2015 and 2016 in the Computer Science Department, Girls Main Campus (GMC) branch from the following perspectives: the project plan and deliverables at each milestone, and the provision of constructive mature collective feedback by the evaluating committee. These refinements are called addendums as they are additional steps to the SPMS and each step is monitored by using forms. This paper also describes some practices that support the SPMS along with the rationale behind their application. Evidence for the two addendums have been collected from analysis of the relevant forms. The analysis showed that the students benefited from the flexibility introduced by the milestone addendum as they made use of the new options. In addition, analysis of the forms of the feedback addendum showed that this documentation served as a means to gather the overall collective opinion of the committee members as opposed to the individual assessment of each member. Additional evidence was collected from evaluation committee members, by conducting a questionnaire. It showed that participants do benefit from the discussion promoted by the feedback addendum.
\end{abstract}

Index Terms-Computer Science (CS), Senior Project Management System (SPMS), Milestones, Feedback.

\section{INTRODUCTION}

The senior project is an essential component of the Computer Science (CS) curriculum of the Faculty of Computing and Information Technology at King Abdulaziz University (KAU). It is a year-long project divided into two courses: CPCS 498 and CPCS 499 [1]. It reflects the knowledge and skills acquired by students during the past three years within the college and the department. In this paper, the focus is on the project management aspect of senior projects imposed by the department and study how it supports students in carrying out their projects. In the CS department in KAU, a general but detailed system has been defined by an assigned committee dedicated to the purpose of managing the senior projects. In addition to defining the process, the committee has also designed a set of supporting forms along with the necessary documentation.

As quality assurance is part of our routine, the application of the Senior Project Management System (SPMS) has been observed and the detailed needs that have arisen have been documented. After careful analysis of these needs, some addendums were designed and then applied in the following cycle. The aim of this paper is to present a study of two main addendums, in addition to reporting some of the practices that have proven to be useful. The first addendum is to allow for students to choose the methodology that best fits that of their project; hence the deliverables in the predefined milestones should be customized to reflect the chosen methodology and documented in the Milestone form. The second addendum is to document the general opinion of the evaluating committee in what is called the feedback form.

The effect of these two addendums has been studied by analyzing data found in the relevant forms. The second addendum has been supplemented by a questionnaire conducted by doctors who participated in evaluating senior projects and taking part in applying the change. 
The outcome of this study has been seen to be twofold, first it is noticed that the two addendums have helped to enrich the experience of senior project management. The feedback form has met some of the objectives for which it was designed for. The second outcome has been deriving the categories of the feedback collected from the dedicated forms. It is hoped that such information may provide a useful basis for improving the rubrics used for evaluation.

The rest of this paper is organized as follows: section II presents a review of the related work about SPMSs. In section III, a general description of the SPMS in the CS department in KAU is presented. In section IV, we present the two addendums. We describe some practices that are applied along with the rationale underlying their application in section V. In section VI, the paper is concluded.

\section{RELATED WORK}

The general umbrella of the related work presented in this section is the SPMSs. In this section, a review of the following topics is presented: project idea, quality of senior projects, technology aids for SPMS, project methodology, project assessment activities, and practices that are common in SPMS. Fig.1 shows the hierarchy of these covered topics, where topics in green represent work that is related to the two addendums described in Section III and the practices described in Section V.

Designing and managing senior projects is a challenging task, especially as it involves the interaction of different parties: the students, advisory team and evaluation team at minimum. In addition, such major projects deal with open-end investigation as opposed to pre-defined course syllabus with controlled exercises.

The challenging nature of senior projects has inspired many to document this experience as in [2-6]. Most of the characteristics of Senior Projects are covered in [7], in which all possible varieties are listed, such as different assessment methods, objectives of adding a senior project in the academic program plan, and defined deliverables. The choice remains with academic institutes as to which combinations would suite their specific objectives.

In [8], the authors reported their experience in defining the structure of the capstone course in response to the new standard curriculum applied in their department. Design decisions were reported, such as whether to group students into pairs, allow for research-focused topics and add emphasis on soft skills in conducting projects.

Quality is a key concern in higher-education institutes and some authors have reported the effect of quality assurance systems - aka accreditation systems - on the design of senior projects. In [2], the authors reported the design of their SPMS after their shift to outcome-based learning as fulfilment of a requirement of the accreditation systems. Moreover, authors in [3] described a SPMS that supports students in demonstrating their ability to develop projects that have sound designs with respect to their scale and quality. This degree of quality is an accreditation requirement that proved to be challenging to satisfy in an environment that have weak connections with industrial bodies.

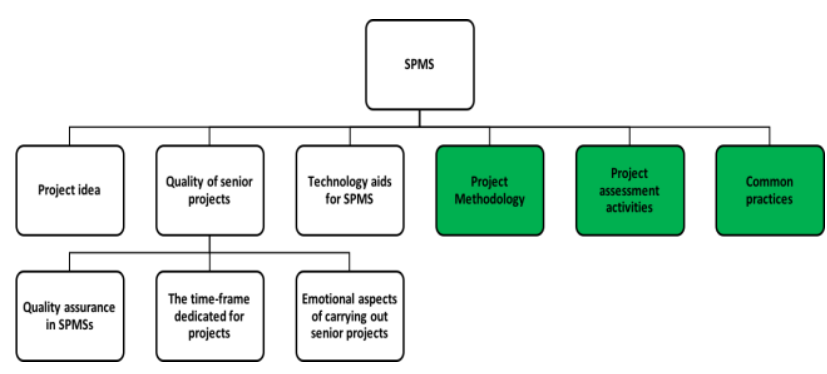

Fig. 1. The hierarchy of topics covered in section II.

Attention is given to project ideas. Some reported their selection process, as in [9] and [5]. Examples of projects conducted during 10 years in Okanagan college has been reported in [10]. Authors in [4] noticed that students have high motivation and engagement in the project when they are the owner of the project idea. They have described a report of a success story of a project, where the topic was suggested by the student. The project idea opened many interesting computational and ethical questions, and eventually provided an informative learning experience. However, the authors concluded that not all students suggest good ideas and even ideas proposed by students likely need refinement by their supervisors. Authors in [11] highlighted an issue related to the collective value of the senior projects conducted by a department. Having diversity in the domains and applications in the projects' ideas waste time and effort on small-scale products. The authors proposed to focus on specific limited areas of specialties that serves certain lines of applications aligned with identified national needs; doing so, they believe it will change the way projects are selected, conducted and invested in industry.

One important factor affecting the quality and scale of the project is the period assigned to complete the project. Many institutes dedicate two consecutive courses for conducting senior projects. In [6], the senior project course lasts only one term. This has led to lots of challenges, one of them being the need to design a suitable methodology that follows the water fall model, but with some iterations among phases. The authors recommend some of the solutions they have used and believe that courses with one-term projects can benefit from them. However, it has been concluded that spreading the senior project over two terms may allow for more mature products. Another approach goes so far as to add an optional pre-term with students starting the project as part of the assignments assigned by a course such as a software engineering course [12].

Recent studies have focused on the emotional aspect of conducting senior projects on students, such as the study found in [13]. The authors believe that their findings may assist in developing CS programs, especially as the consequence of the engagement and investment students put in their projects is having real-world impact outcomes.

Technology can be used to improve the quality of the SPMS. In [14], a description of a system for tracking students using mobile and GPS technologies is presented. 
The goal is to assist in monitoring and grading the progress of students as they visit clients where the engineering product will eventually be deployed. Another tool described in [15] focuses on planning and monitoring tasks, such as managing documentation and forms; additionally, it provides a social network that helps in exchanging experiences among members especially for senior projects that have similar profiles.

One aspect reported in the literature is the methodology that students should follow to reach the outcome of their project. The author in [16] explained that the quality of the process which applies a methodology influences the quality of the project's outcome as the process addresses issues of maintainability, following standards and ensuring the ability of the product to adapt to new changes after delivery. It is worth noting that the author has also identified having a degree of professionalism in applying practices as important as the product and process in determining the quality of the senior project. In [17], the authors analyzed the performance of students from their perspective, their supervisors and their evaluators perspectives as well. They have placed methodology under the student's competence category, as methodology is considered a key factor in determining the success of a project. Authors in [18] focused on SPMS from the project management aspect. They have showed that applying a structured and systematic process, called Meeting-Flow, to organize and conduct meetings improved teamwork quality. In [19], the deployment of Scrum framework in senior projects is studied, it is found that high-performing students were keen in applying Scrum practices, whereas low-performing students overlooked them. Reference [8] also reported the use of Scrum. Authors in [20] applied and analyzed Agile Scrum model and IScrum process model on a case study of two senior projects. Author in [21] highlighted that selection of the methodology to be applied should be based on how close it fits the needs of the project. This is one of the main reasons for introducing the milestone addendum in our SPMS.

Assessment of student performance has also been discussed thoroughly in the literature, be it formative or summative. In [22], a concern was raised as beliefs among instructors vary with some instructors assisting students and providing feedback before grading and others opting for summative assessment and no feedback. This causes a degree of unfairness in grading different students. Authors in [23] reported a six-component system for assessing senior projects. The components are: meeting records, the abstract, the initial proposal, the interim report, the oral presentation and Engineering Fair. They also emphasized that timely feedback from evaluators be given to students as part of the assessment system. Rubrics are used to provide a unified way of assessment of projects. The rubrics used for the Software Specification Phase are described in [2]. One of the major concerns of assessment in projects is giving fair grades to individual students working within a team on a project, more specifically preventing rewarding free riders who are part of the team but do not contribute to the project. Authors in [24] developed a software tool called SPARK, dedicated to documenting the assessment of the performance of the students themselves and their peers by comparing assessment entries to Benchmarks. Although it has been reported that its use is exhaustive, the majority of the study sample thinks its strength is in self-reflection as opposed to stopping free-riders [25]. Reference [22] reported that having external bodies that provide feedback on quality of senior projects, annually and every five years, has been a source of confidence in the quality of the hosting academic programs. This sort of evaluation is relevant to our feedback addendum as both reflect back to some aspect of senior projects. However, comparing the practice done by the college reported in [22] and our feedback addendum, we found two points of differences: the source of data being inspected or analyzed and the goal of analysis. They are reflecting back on the quality of the senior projects through their documentation and for the sake of judging the quality of the program. In our feedback addendum, we reflect back on status of the senior projects through the opinion of the evaluation committee for the sake of improving prospectus assessments.

In section VI, some proven useful practices have been reported. Authors in [5] have also reported their reflections on ten years of running senior projects in Brigham Young University (BYU). They have provided valuable lessons about managing Intellectual Properties, facing technical problems and the different degrees of cooperation students get from sponsors. They also described the mechanism used to distribute project ideas among students' groups. Groups are formed by students selecting the projects' that interest them rather than determining the team-members first. They also identified three perspectives that determines the success of a project: the learning experience it provides, team and project management aspects and the project objectives.

Additional practices reported in the literature, is allowing or encouraging research topics in senior projects [8], publishing papers in conferences [10], presenting projects to audiences such as doing poster day [10] and [8], or Engineering Fair [22], the use of version control systems [21], such as the systems reported in [8] and [10] and enriching the senior project experience by including student reflection activities such as maintaining Portfolios [26], [27], and [21].

\section{ThE GENERAL PROCESS}

The Senior Project spans a whole year - two academic terms - and is divided into CPCS 498 and CPCS 499. Course description is defined and documented. The system defines three roles to run the projects by academic staff: The Supervisor, the Academic Coordinator and the Evaluation Committee. In each course, the 100 marks are divided into 30, 30 and 40 and distributed among the above roles; respectively. The process is basically the same in both courses; however, CPCS 498 focuses more on determining the key elements of a proposal and the 
initial phases of a project such as conducting a literature review and then the analysis; whereas CPCS 499 focuses more on developing and testing the product. The following activities are involved in delivering the objectives of each course:

- Teaching activities: giving lectures along with referral to a textbook.

- Report and presentation evaluations: there are two mid-milestones to be evaluated by the coordinator and one final evaluation to be done by the committee.

Next, official forms are described, they are listed according to staff roles:

The supervisor is asked to sign the team formation form, to fill in the weekly progress report form, as well as part of the aggregative form (to be explained later on).

The coordinator is responsible for filling in the two milestones' evaluation forms that focus on style and ontime submission. They also fill in their part of the aggregative form.

The evaluation committee is responsible for filling in the evaluation form following the guidelines of the official rubric.

There is a peer-evaluation form that is not assigned any marks, however, it should influence the supervisor's decision in allotting grades.

By the end of each course, all marks are gathered in the aggregative form and the final grade is computed.

In general, all forms are the same in both courses; however, there are two additional forms in CPCS 498. One form is used to determine if the student is eligible to register for CPCS 498 or not and it must be signed by the academic advisor of the student. The second form is considered as a contract between the team and the department, specifying the supervisor of the project, the team members and their leader, and the topic of the project. Table 1 illustrates the departmental-level activities that are part of both courses CPCS 498 and CPCS 499. The detailed mark distribution of the 30 marks dedicated to the coordinator and the supervisor will have slight changes based on the different tasks assigned in each course.

\section{THE Two ADDENDUMS}

As the SPMS activities are under operation, some new needs have surfaced that require intervention. Two of them are explained in this section. In section IV.A, we describe the milestone addendum that addresses the need for flexibility in determining the kind of methodology to be applied in a senior project. In section IV.B, we describe the evaluating committee feedback addendum that addresses the need for exchanging evaluation experience without the pressure of imposing a certain grade on any member of the committee.

\section{A. Milestone Addendum}

The determined milestones serve the important goal of forcing students to focus, organize their ideas and generate useful deliverables that make submitting a full report by the end of the term an achievable target. However, it is observed that following the general template milestones causes some distractions as the students find it difficult to use the required deliverables as aids to reach the ultimate product, especially, if there is incompatibility between some of the required deliverables and the kind of the projects, whether it be a software engineering project, a graphics project, etc.

Table 1. Department-level senior project activities

\begin{tabular}{|c|c|c|}
\hline Time-line & \multicolumn{2}{|l|}{ Department-level Project Activity } \\
\hline $\begin{array}{l}\text { Pre-CPCS } \\
498 \text { term }\end{array}$ & \multicolumn{2}{|l|}{ Induction Activities** } \\
\hline \multirow[t]{2}{*}{ Week 1} & Eligibility form submission* & \multirow{6}{*}{$\begin{array}{l}\text { Weekly } \\
\text { Progress } \\
\text { Report } \\
\text { (minimum } \\
10 \text { reports) }\end{array}$} \\
\hline & Senior project registration & \\
\hline Week 3 & Initial presentation* & \\
\hline Week 6 & Milestone form submission** & \\
\hline Week 8 & $\begin{array}{l}\text { Milestone 1: report submission and } \\
\text { presentation }\end{array}$ & \\
\hline Week 12 & $\begin{array}{l}\text { Milestone } 2 \text { : report submission and } \\
\text { presentation }\end{array}$ & \\
\hline & Report submission & \\
\hline Week 15 & Project discussion & \\
\hline & Post-discussion feedback** & \\
\hline $\begin{array}{l}* \text { activities } \\
* * \text { the ame }\end{array}$ & $\begin{array}{l}\text { ific to CPCS } 498 \\
\text { nts introduced to the system }\end{array}$ & \\
\hline
\end{tabular}

In order to tackle this difficulty, some flexibility is added by providing adjustable milestones. The number of milestones and dates are fixed; however, the methodology and deliverables are determined by each individual student group. Two factors motivate this change: the support of different kinds of methodologies, and the support of different kinds of projects, such as software engineering projects, graphic design projects, networks project, etc. Both factors affect which deliverables should be submitted in each milestone. To support the new regulation, a new form shown in Fig. 2. has been defined.

The form spans the milestones of the whole project which covers the two terms. The form should be submitted two weeks before the first deliverable in CPCS 498. Each group should determine the methodology they will follow and the deliverables that will be submitted at each milestone. A reference must be stated describing the chosen methodology. Students may choose a methodology that follows one of the Software Life-Cycle models, such as the Spiral or Phased models. The option to follow the original template - that follows the Waterfall model - defined by the system is still available.

A study has been made on the milestone forms that were collected during the year 2016. There were 13 projects. Fig. 3. shows the different methodologies chosen for all projects. 
The analysis of the contents of the forms has resulted in the following observations: one project has no correspondence between methodology and chosen deliverables, as the chosen deliverables reflect phases that are inconsistent with the methodology. Some forms have explained the chosen methodology very clearly in a mature way showing good correspondence between the steps of the methodology and the determined deliverables at each milestone. Most groups who chose a methodology other than the waterfall model realized that they should start implementation during CPCS 498, and some, actually, did. Projects that have not used the waterfall model chose a form of the iterative approach. Two of these projects chose an iterative methodology that is specific for developing mobile applications. This shows that one of the factors that influenced the student's decision is the kind of platform they are using to implement their application. It is worthy to note that groups who used the waterfall model had non-scientific reasons for their decision. Some of the groups had new supervisors who preferred to get acquainted with the SPMS first, then start fiddling with its advanced options. Some supervisors preferred to focus the challenge for the students on determining the tasks and implementing them and not spend time on new process knowledge. In other cases, the students backed away from using agile approaches to avoid the possibility of doing implementation in CPCS 498. This shows that adding a suggested simple template provides some sort of flexibility as well. We also found that Computer Vision projects, even though supervised by different supervisors, had chosen the spiral model which enables them to develop a prototype early in the process to validate their theory.

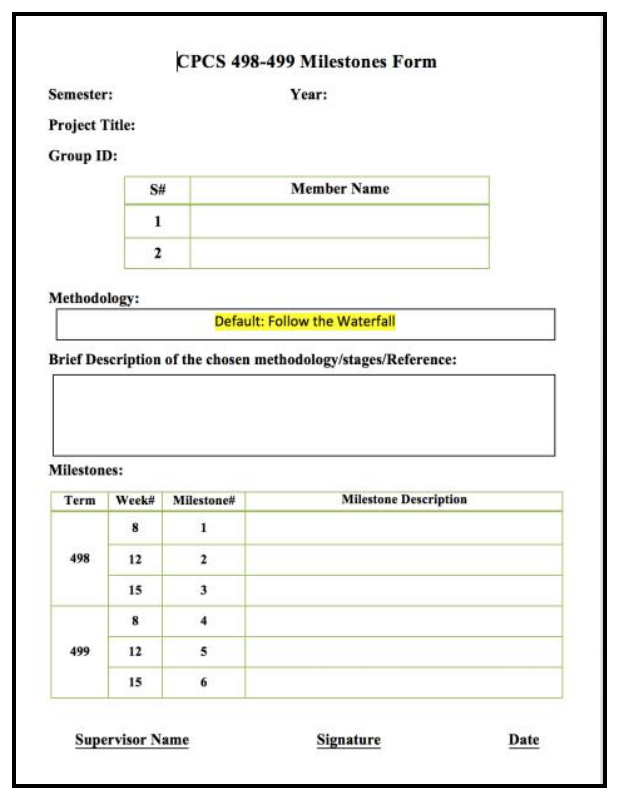

Fig. 2. The Milestones form.

In conclusion, $69 \%$ of the groups have chosen a methodology different from the waterfall model. This proves that there is a need for the flexibility introduced by the addendum of the milestone step. It is envisaged that this step has contributed also to the quality of the final product as the groups started implementation according to a standard methodology early in the process. Another issue is that the divergence among the chosen methodologies shows that groups actually tried to find the most suitable methodology for their project, as opposed to a previous period where all groups used to choose one single methodology as taught in one of their courses. An important outcome of this change is that students had an opportunity to practically exercise the application of methodology and feel tangible effects of their decisions.

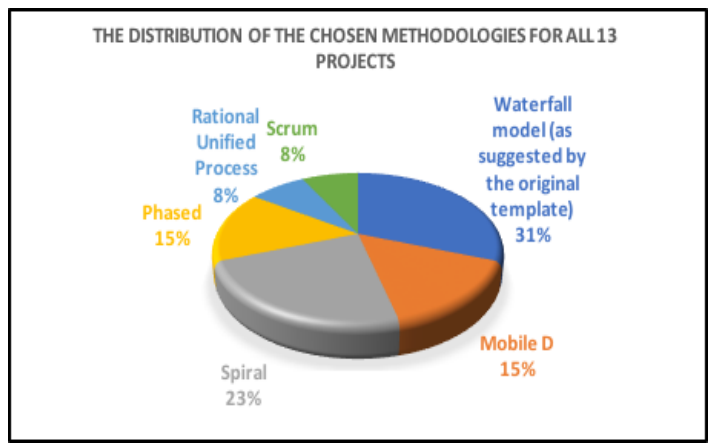

Fig. 3. The Distribution of the Chosen Methodologies for all 13 projects

\section{B. Feedback addendum}

Assessment is one of the pillars of the SPMS and in this paper the focus has been on the assessment given by the evaluating committee. Each member submits a grade for the project out of 40 following the grade distribution and levels defined by the official rubric. The overall committee grade for a project is computed as the average of the grades given by all committee members. However, as the kinds of projects, student performance, discussion circumstances, and the level of experience among the evaluating member vary a lot among projects, committee members need to exchange opinions and discuss the performances with other committee members. Members wish to ensure that they are being fair and following the rubric accurately but with awareness of the special details of the project being assessed. To address this need, a post-discussion step has been added to the SPMS. The details of the step are illustrated in Table 2, and the Feedback form is shown Fig. 4. The goal of this step is to promote discussion among committee members while-as with the original system-still preserving the freedom of members to choose the grades they believe represents the student performance; i.e. there is no pressure from the supervisor or other committee members in determining the grades.

This degree of transparency promoted by exchanging opinions can help in improving the current system of assessment. As described in Table 2, Part 1 of the feedback form documents the strengths and weaknesses of the projects and Part 2 gathers information about the extendability of the project. The committee responsible for running the SPMS in our department can gather the information found in the feedback form of all senior projects and make use of it to improve the system. The 
information found in Part 1 can be utilized to improve the rubrics, whereas the information found in Part 2 can be utilized differently depending on which phase of the project the comment is given. Comments gathered from CPCS 498 forms can be used to improve the final product of the current project, whereas comments gathered from CPCS 499 forms can be used to give ideas of new projects for students in successive classes.

After analysis of the two parts of feedback forms of a sample of the CPCS 498 and CPCS 499 projects (14 CPCS 498- 8 CPCS 499-total:22 form), the following observations were noticed:

Table 2. The Details of the Feedback Step

\begin{tabular}{|l|l|}
\hline The Timing & $\begin{array}{l}\text { At the end of the project final discussion } \\
\text { in CPCS 498 and CPCS 499. }\end{array}$ \\
\hline $\begin{array}{l}\text { The } \\
\text { Participants }\end{array}$ & $\begin{array}{l}\text { The evaluating committee. The supervisor } \\
\text { should not be present during this step to } \\
\text { ease the discussion among the committee } \\
\text { members. }\end{array}$ \\
\hline $\begin{array}{l}\text { Part 1 of the } \\
\text { discussion }\end{array}$ & $\begin{array}{l}\text { The strengths and weaknesses of the } \\
\text { project }\end{array}$ \\
\hline $\begin{array}{l}\text { Part } 2 \text { of the } \\
\text { discussion }\end{array}$ & The extendability of the project \\
\hline Documentation & $\begin{array}{l}\text { The two parts are documented by the } \\
\text { committee head in the feedback form and } \\
\text { signed by all members, then submitted to } \\
\text { the coordinator. }\end{array}$ \\
\hline
\end{tabular}

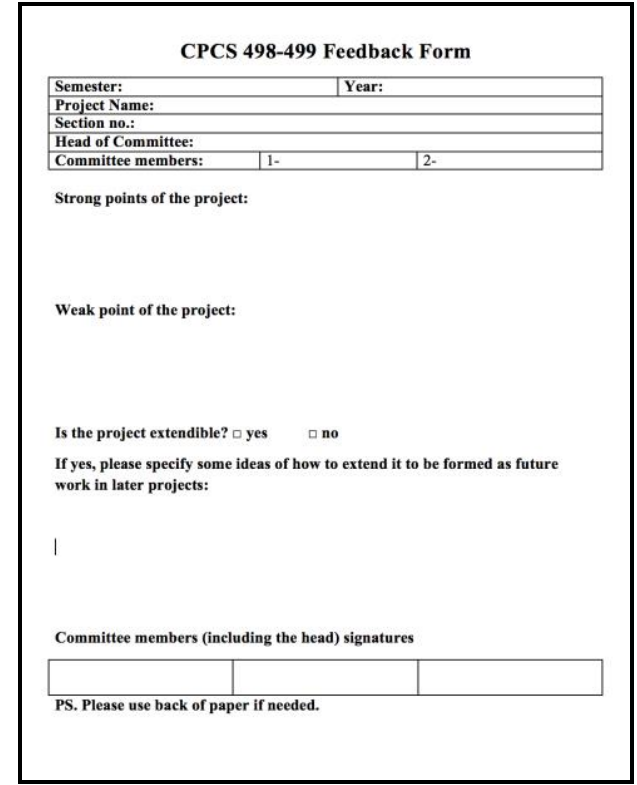

Fig. 4. The Feedback form.

\section{Observations related to the strengths and weaknesses part:}

The comments determine the component that the committee members see as strong or week without detailed explanation. The components referred to as strong are the idea, report and the overall product itself. The component, also, may be one of the software engineering phases including the analysis phase, the design phase and the testing phase. The highlighted phase may be listed under strengths or weakness of the project. Another aspect explained in the weakness part is the request to add a specific part of the functionality that may be as small as a command or as large as a subsystem. Missing features, and certain modifications to features have also been reported in this part.

\section{Observations related to the extendability part:}

The comments found in the extendibility part in CPCS 498 and/or CPCS 499 are grouped into the following categories:

- Requesting to add extra functionality that is the size of a command, for example, the request to add the functionality of rating the photographer's role in a social network dedicated to wedding services, where photography is a peripheral service in the application.

- Critiquing a project as being weak and missing essential features, for example a project in CPCS 498 designs a social network that serves as a pregnancy guide and allows sharing experiences. However, it does not provide any extra functionality from the available general purpose social networks, to necessitate developing a custom-made social network. Another project that should represent a financial supervisor was missing the functionality of budget planning. In CPCS 499, the project had problems in implementation as it implemented the main menu and the screens and database for some of the functionalities but was missing the necessary link between functionalities that completes a business procedure.

- Requesting to improve certain phase in the methodology, such as analysis and design. For example, some comments suggested adding more user roles to perform usability testing.

- Requesting to amend an existing feature, for example, in an application for path finding, a request was made to change destination dynamically instead of choosing predefined paths. This kind of feedback is only found in CPCS 498.

- Recommending the extension of the current project to develop a new project. For example, the request to integrate two related applications and the request to add intelligence to an application so that it can make decisions on behalf of users. This kind of feedback is only found in CPCS 499.

- Recommending the improvement of the quality of research results to become more challenging. For example, a request to minimize user intervention in the strategy of identifying obstacles in a Robot. This kind of feedback is only found in CPCS 499.

In general, the feedback in the extendability part can be broken into requests and recommendations. The requests must be fulfilled to get better grading and recommendations are optional. Recommendations are usually meant to improve the quality of the current product or to increase the knowledge and experience of the students. The criticism of weak projects serves as a warning for CPCS 498 project. However, if such 
criticism is given in CPCS 499 then it serves as an alert for the committee running the SPMS to investigate the case in order to take prevention measures in the future.

3. It is noted that evaluators list extra functionalities sometimes in the weakness part and other times in the extendability part. In addition, it is seen that the given feedback is too brief as the evaluators are usually in a hurry and wish not to give time more than the task deserves according to their priorities.

In addition to collecting data from forms, a questionnaire has been designed to ensure that the feedback step meets its objectives. The responses of all evaluators (11 evaluators) were collected. The objectives of the questionnaire are as follows:

Objective1: check whether the evaluators benefited or not from the discussion among those in the evaluation committee.

Objective2: check whether the evaluators still maintain the freedom of determining project grades without the pressure of other committee members or the supervisor of the project.

Objective 3: check whether the components of the form (strengths, weaknesses and extendibility parts) summarize the relevant ideas of the evaluation committee discussion.

Table 3 presents the summary of the questionnaire results. As reported in Table III, answers to Q1.1 show that all evaluators found the post-discussion useful. 9 evaluators out of 11 had been influenced by the postdiscussion as reported by answers to Q1.2. These 9 evaluators were directed to two additional questions, $\mathrm{Q} 1.2 .1$ and Q1.2.2, to check in what sense they were affected. The evaluators answers to these questions show that 8 evaluators felt they are more confident with their grade decision and 5 evaluators reported that they actually changed the grade they had in mind after the post-discussion. Answers to Q2.1 show that 10 evaluators out of 11 found it convenient that the post-discussion does not force a single unified decision regarding the grade that should be given to the project, whereas answers to Q2.2 show that 8 evaluators believe that it is important for the supervisor to attend the Post-discussion. As for the questions related to objective 3, the results of Q3.1 show that over 9 evaluators believe that the strengths and weaknesses part should remain as components of the feedback form of the CPCS 498 course. However, 7 believe that the extendability part is an important component of the form in this course. Answers to Q3.2 also illustrate that more than 8 evaluators believe that the strengths, weaknesses and extendability parts should remain as components of the feedback form of the CPCS 499 course.

From the previous summary, we learn that the feedback step has met the objectives of benefiting the evaluators from the post-discussion in ensuring the fairness and objectivity of their own judgment, and maintaining the freedom of giving a grade without the pressure of the supervisor or the committee. Additionally, the components of the feedback form proved to be an adequate summary of the ideas of the post-discussion, even though there is some hesitancy regarding the extendibility part especially in CPCS 498 feedback form.

In conclusion, from analysis of the data gathered from the feedback forms and the summary of the questionnaire results, the feedback form proved an asset to the SPMS as it enables committee members to benefit from each other's opinions and experience.

An additional outcome, is that the feedback form provided a useful tool in gathering the collective opinions of all committee members in one place. The categories derived can be used to upgrade the levels defined in the official rubric.

\section{USEFUl PRACTices}

In this section, we describe some of the practices that are applied specifically in the Girls Main Campus GMC and explain the rationale underlying their application. The practices are as follows:

\section{a) Induction period:}

This is the term before registering for the CPCS 498 course, candidates who are eligible to register for the course are determined. A communication method is established with all students as a group, to ensure they all receive important announcements. One meeting is done to instruct students to form groups while stating the maximum and minimum accepted size of a group. A group leader must be specified. Students are advised to choose a supervisor that is willing to accept their group. A list of available doctors is presented along with their contact information. Details of the process and forms to be submitted are explained to the students with pointers as to where to get further information. Three key elements to be determined are the team members, the supervisor and the topic; an interrelated decision where the choice of one element affects the other. However, as a department we must receive the decision on the team members and the supervisor but delay the topic decision to the next stage and encourage teams to work hard to determine the topic as early as possible. The main goal of this process is to have students ready to commit to the specified deadlines. In order to give insights of project ideas and trigger the enthusiasm of new senior project students, examples of successful previous projects are presented by the graduates themselves. Any prestigious prizes won are also presented. To further support new students, previous graduates are also asked to provide technical support in using development tools.

A further step is to trigger this quest into freshmen students' minds as soon as they join the college. We encourage them to search for the topic of the project that will later on play an important role in their job interviews. Furthermore, to inspire students to prepare challenging ideas for their projects, department's official glorifies all regional and international accomplishments of senior project students, such as earning prizes and publishing 
papers. This recognition of accomplishment is done in a timely fashion as soon as the prize is awarded, or the paper is accepted.

\section{b) Refinement of the project idea:}

A well-established practice is applied where each group of students presents the topic of their project to all doctors that belong to GMC branch. The goal is to enrich the idea of the project and approve it as a potentially promising project. It is realized that criticizing the project at this stage - week 3 in the academic term of CPCS 498 - would possibly make room for improvements to be applied.

Table 3. Summary of the Feedback Step Questionnaire Results

\begin{tabular}{|c|c|c|}
\hline Objectives Questions & "Yes" \% & "No" \% \\
\hline \multicolumn{3}{|l|}{ Objective 1} \\
\hline Q1.1 Do you find the post-discussion among the committee members useful? & $100 \%$ & $0 \%$ \\
\hline \multirow{3}{*}{$\begin{array}{l}\text { Q1.2 Has the post-discussion influenced your opinion about the project in any sense? } \\
\text { Q1.2.1 Has the post-discussion made you feel more confident and convinced of the grade you have chosen for } \\
\text { the project? } \\
\text { Q1.2.2 Has it happened that at least once the post-discussion helped in altering the decision you had in mind as a } \\
\text { grade for the project? }\end{array}$} & $82 \%(9)$ & $18 \%(2)$ \\
\hline & $89 \%(8)$ & $11 \%(1)$ \\
\hline & $56 \%(5)$ & $44 \%(4)$ \\
\hline \multicolumn{3}{|l|}{ Objective 2} \\
\hline $\begin{array}{l}\text { Q2.1 Do you find it more convenient that the post-discussion does not force a single unified decision regarding the } \\
\text { grade that should be given to the project? }\end{array}$ & $91 \%$ & $9 \%$ \\
\hline Q2.2 Do you believe as an evaluator it is important that the supervisor attend the Post-discussion? & $72 \%$ & $28 \%$ \\
\hline \multicolumn{3}{|l|}{ Objective 3} \\
\hline \multicolumn{3}{|l|}{ Q3.1 Please choose the components that should remain in the (498) feedback form: } \\
\hline Strength & $91 \%$ & $9 \%$ \\
\hline Weakness & $100 \%$ & $0 \%$ \\
\hline Extendability & $64 \%$ & $36 \%$ \\
\hline \multicolumn{3}{|l|}{ Q3.2 Please choose the components that should remain in the (499) feedback form: } \\
\hline Strength & $100 \%$ & $0 \%$ \\
\hline Weakness & $91 \%$ & $9 \%$ \\
\hline Extendability & $82 \%$ & $18 \%$ \\
\hline
\end{tabular}

c) One of the applied practices involves stating explicitly how students dealt with the feedback they received regarding the submitted product as fulfilment of the CPCS 498 course requirements.

This is done at the first presentation of CPCS 499. This step is very important as students deal with the regularities of the capstone project for the first time as previous projects are completed within one-course-span. This requirement raises awareness of the right time to benefit from the received feedback and use it to improve the final product.

\section{d) Plan for graduation:}

The candidate list of students who should register for CPCS 498 is filtered by checking that they have passed certain hours; they should also study the following courses: Software Engineering, Project Management and Database. The hours are roughly computed as the total hours of all years of study except for the final year. However, in some situations, students who still have two years ahead to graduate can actually pass both filters. Some of these cases include students that have transferred from another college or students who need to register for courses without having covered the prerequisites. It is important to exclude such cases, to ensure that students benefit the most from the senior project experience. Hence, each student must submit a plan for their graduation that is revised with their academic advisor to get the departmental approval for registering CPCS 498. The plan shows the number of the remaining terms and the courses expected to be registered for in each term.

\section{CONCLUSIONS AND RECOMMENDATION}

In this paper, we described the general management system for senior projects in the CS department at KAU. We presented some the practices that have proven useful as well. The focus of this paper is to study two addendums to the SPMS. This first addendum is to introduce some flexibility in determining the methodology to follow in the senior project, as the original system assumes the waterfall model as a methodology. After analyzing the milestone forms for 13 projects, it showed that $69 \%$ of the projects had chosen a different methodology. Moreover, it showed that there is diversity in the kinds of methodologies chosen among projects. This shows clear evidence that the introduced flexibility is needed. One benefit of choosing different methodologies is that students become aware of the requirements of their decision and experience the effect of their planning practically, for example, students who applied the iterative approach realized that they should start part of the implementation in CPCS 498.

The second addendum is promoting post-discussion among evaluating committee members in order to share experience and assist in making an informed decision regarding the grade given by the individual evaluator. The results of analyzing the forms show that the committee does reach a common ground regarding the key assessment points for the project; and from the results of the conducted questionnaire, it is shown that all evaluators benefit from the post-discussion step. One of the outcomes of the feedback addendum is that opinions of all members are gathered in one place. 
It is recommended that the committee responsible for running the SPMS in our department make use of the feedback information to improve the senior projects rubrics and ensure that the feedback is communicated with the students and supervisor.

\section{ACKNOWLEDGMENT}

The authors would like to thank Assoc. Prof. Etimad Fadel for her continuous encouragement to complete this work and blessing its importance. Also, the authors wish to show their appreciation to all senior project evaluators who participated in the feedback addendum questionnaire. All participants have been cooperative and provided prompt responses.

\section{REFERENCES}

[1] Faculty of Computing and Information Technology, "Computer Science Department," 15 August 2017. [Online]. Available: http://computing.kau.edu.sa/pagesdepcs-en.aspx. [Accessed 23 October 2017].

[2] M. Vijayalakshmi, P. D. Desai and G. H. Joshi, "Outcome based education performance evaluation of capstone project using assessment rubrics and matrix," 2013 IEEE International Conference in MOOC, Innovation and Technology in Education (MITE), Jaipur, 2013, pp. 6-10.

[3] A. M. Al-Bahi, M. A. Taha and N. Turkmen, "Capstone design projects in the environment of weak industryacademia interaction," 2014 IEEE Global Engineering Education Conference (EDUCON), Istanbul, 2014, pp. 330-334.

[4] Alan Fedoruk, Mingwei Gong, and Michael McCarthy, "Student initiated capstone projects," In Proceedings of the 15th Annual Conference on Information technology education (SIGITE '14), 2014, ACM, New York, NY, USA, 65-70.

[5] Richard G. Helps, Joseph J. Ekstrom, and Barry M. Lunt, "IT Capstone Course Structure for Success," In Proceedings of the 16th Annual Conference on Information Technology Education (SIGITE '15), 2015, ACM, New York, NY, USA, 27-32.

[6] S. M. Dascalu, Y. L. Varol, F. C. Harris and B. T. Westphal, "Computer science capstone course senior projects: from project idea to prototype implementation," Proceedings Frontiers in Education 35th Annual Conference, Indianopolis, IN, 2005, pp. S3J1.

[7] Tony Clear, Michael Goldweber, Frank H. Young, Paul M. Leidig, and Kirk Scott, "Resources for instructors of capstone courses in computing," In Working group reports from ITiCSE on Innovation and technology in computer science education (ITiCSE-WGR '01), 2001, ACM, New York, NY, USA, 93-113.

[8] Andrew Scott, William Kreahling, Mark Holliday, and Scott Barlowe, "A Holistic Capstone Experience: Beyond Technical Ability," In Proceedings of the 18th Annual Conference on Information Technology Education (SIGITE '17), 2017, ACM, New York, NY, USA, 1-6.

[9] M. Vijayalakshmi, P. D. Desai and G. H. Joshi, "An innovative approach to problem identification and design for capstone projects," 2012 IEEE International Conference on Engineering Education: Innovative Practices and Future Trends (AICERA), Kottayam, 2012, pp. 1-5.
[10] Youry Khmelevsky, "Ten Years of Capstone Projects at Okanagan College: A Retrospective Analysis," In Proceedings of the 21st Western Canadian Conference on Computing Education (WCCCE '16), 2016, ACM, New York, NY, USA, Article 7, 6 pages.

[11] K. Malur, Alumnus, P. Meena and R. Deekshit, "A transformative approach to capstone projects in engineering," 2014 IEEE International Conference on MOOC, Innovation and Technology in Education (MITE), Patiala, 2014, pp. 348-351.

[12] Xuguang Chen, "Redesign of a senior software engineering course with dual projects," J. Comput. Sci. Coll. 33, 1 (October 2017), 194-201.

[13] R. Parker, "How Do You Feel: Affective Expressions from Computer Science Senior Capstone Projects," 2017 International Conference on Learning and Teaching in Computing and Engineering (LaTICE), Hong Kong, 2017, pp. 35-42.

[14] S. Kadry, "A novel design of management senior project for engineering students," 2015 IEEE Global Engineering Education Conference (EDUCON), Tallinn, 2015, pp. 812-817.

[15] J. J. Olarte, C. Domínguez, A. Jaime and F. J. GarcíaIzquierdo, "A tool for capstone project management in computer science engineering," 2014 International Symposium on Computers in Education (SIIE), Logrono, 2014, pp. 65-68.

[16] Tony Clear, "Thinking ISsues: the three p's of capstone project performance," SIGCSE Bull.41, 2 (June 2009), 6970.

[17] J. J. Olarte, C. Domı'nguez, A. Jaime and F. J. Garci'aIzquierdo, "Student and Staff Perceptions of Key Aspects of Computer Science Engineering Capstone Projects," in IEEE Transactions on Education, vol. 59, no. 1, pp. 4551, Feb. 2016.

[18] C. Y. Chen, Y. C. Hong and P. C. Chen, "Effects of the Meetings-Flow Approach on Quality Teamwork in the Training of Software Capstone Projects," in IEEE Transactions on Education, vol. 57, no. 3, pp. 201-208, Aug. 2014.

[19] M. Paasivaara, J. Vanhanen, V. T. Heikkilä, C. Lassenius, J. Itkonen and E. Laukkanen, "Do High and Low Performing Student Teams Use Scrum Differently in Capstone Projects?," 2017 IEEE/ACM 39th International Conference on Software Engineering: Software Engineering Education and Training Track (ICSE-SEET), Buenos Aires, 2017, pp. 146-149.

[20] Sara Ashraf, Shabib Aftab, "Pragmatic Evaluation of IScrum \& Scrum", International Journal of Modern Education and Computer Science(IJMECS), Vol.10, No.1, pp. 24-35, 2018.

[21] Tony Clear, 'THINKING ISSUES: A 'potted guide' to quality assurance for computing capstone projects," $A C M$ Inroads 2, 2 (June 2011), 14-15.

[22] Jeff Jawitz, Suellen Shay, and Rob Moore, "Management and assessment of final year projects in engineering". The International Journal of Engineering Education. Vol. 18, No. 4, pp. 472-478, 2002.

[23] Tien D.T.K., Lim S.C., "Assessment and Feedback in the Final-Year Engineering Project," In: Tang S., Logonnathan L. (eds) Assessment for Learning Within and Beyond the Classroom. Springer, Singapore, 2016.

[24] Freeman, M. and McKenzie, J., "SPARK, a confidential web-based template for self and peer assessment of student teamwork: benefits of evaluating across different subjects," British Journal of Educational Technology, 33: 551-569, 2016. 
[25] K. Willey and Anne Gardner Rees, "Changing Student's Perceptions of Self and Peer Assessment". Proceedings of the Research in Engineering Education Symposium, 2009, pp. $1-9$.

[26] Guangzhi Zheng, Chi Zhang, and Lei Li.," Practicing and Evaluating Soft Skills in IT Capstone Projects," In Proceedings of the 16th Annual Conference on Information Technology Education (SIGITE '15), 2015, ACM, New York, NY, USA, 109-113.

[27] Juan José Olarte, César Domínguez, Francisco José García-Izquierdo, and Arturo Jaime, "Capstone projects in computer science: evaluated by stakeholders," In Proceedings of the 2014 conference on Innovation \& technology in computer science education (ITiCSE '14), 2014, ACM, New York, NY, USA, 345-345.

\section{Authors' Profiles}

Mai Fadel is a lecturer in Software Engineering at the Department of Computer Science, King Abdulaziz University. Her research interest lies in Design Patterns, and software engineering in general, cloud computing and news credibility in social networks and High-Performance Computing (HPC). She has taught courses in software engineering, web development, algorithms and Java programming. Dr. Mai was the Head of the Information System (IS) and the Computer Science (CS) departments between 2009 and 2016. Dr. Mai received her PhD degree in Computer Science from the Department of Computer Science at the University of Exeter, UK. She is a member of IEEE and ACM.

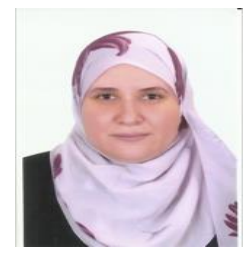

Lamiaa A. Elrefaei received her B.Sc. degree with honors in Electrical Engineering (Electronics and Telecommunications) in 1997, her M.Sc. in 2003 and Ph.D. in 2008 in Electrical Engineering (Electronics) from faculty of Engineering at Shoubra, Benha University, Egypt. She held a number of faculty positions at Benha University, as Teaching Assistant from 1998 to 2003, as an Assistant Lecturer from 2003 to 2008, and has been a lecturer from 2008 to date. She is currently an Assistant Professor at the faculty of Computing and Information Technology, King Abdulaziz University, Jeddah, Saudi Arabia. Her research interests include computational intelligence, biometrics, multimedia security, wireless networks, and Nano networks. She is a senior member of IEEE.

How to cite this paper: Mai A. Fadel, Lamiaa A. Elrefaei, " Adjustments of Methodology Planning and Assessment Activities of Senior Projects in the Computer Science Program", International Journal of Modern Education and Computer Science(IJMECS), Vol.10, No.2, pp. 16-25, 2018.DOI: 10.5815/ijmecs.2018.02.02 